\title{
The Need for a Whole Life Framework in Electrical Power System Asset Management and the Problems with Individual Silo like Asset Management System Contributions
}

James Bruiners*

Robert Gordon University, London, London UK

\begin{abstract}
The asset management of electrical power systems both in industry and academia currently offers up a wide spectrum of engineering practices and guidance to detect, diagnose and to combat asset deterioration. In doing so research largely aims to better enable enhanced decision or prediction making in single engineering applications such as partial discharge or dielectric condition measurements. This paper reviews the current state of the art as related to electrical asset management and sets out how todays engineering and maintenance heavy approaches are insufficient to meet the nature of the complex adaptive (Generation, Transmission \& Distribution) systems. Furthermore this paper explains the need for a truly holistic governance framework capable of managing such complexities for power companies by using complex adaptive system science whilst grounded in the engineering, business and socio-technical attributes that applied engineering makes possible. In addition this paper outlines how utilising retroductive case study with hypothesis framework represents the best approach in creating such a fully holistic asset management capability for power companies.
\end{abstract}

Keywords: Framework; Electrical; Power; System; Asset

\section{Introduction}

This paper is concerned with exploring the topic of asset management for power companies and in doing so will forge the basis of justification for research in applied physical asset management of power systems assets in more holistic capabilities. It will also serve as means of representing the research methodologies utilised across the scientific community whilst including other important factors such as relevant industry and market conditions. Thus presenting the relevant findings and highlighting gaps in research, industry and furthermore present such information in light of the current state of the art as compared to the aims, objectives and proposal subsequently outlined in this paper. The overarching literature considerations are purposely designed to take a blended approach to the wider contributions in Asset Management, utilising a mixture of system engineering practices and making use of cognitive and requirements alignment techniques as described by the likes of Kirova et al. [1] and Mazak et al. [2] in providing a solid mechanism for a 'traceability matrix'. In addition to other inputs such as from complex adaptive system ideologies and concepts [3-5].

The specific aims and objectives of this paper are to provide a holistic management framework that will ensure a power company can effectively manage its physical assets across the entire lifecycle. That consists of the ability to manage in a more agnostic manner, whilst not ignoring prevailing and evolving organisational contributions and advancements. Furthermore this paper will highlight the necessary legacy components and outline how to aid the power company to continually improve towards optimised critical factors such as Risk, Cost and Human factors in doing so.

In March of 2016 an analysis of related scholarly papers and articles related to asset management was performed, this was taken across a ten year period from 2005 to 2015. Two key search terms "Holistic Asset Management" and "Power Systems Asset Management" were performed. In the first instance a mere thirty two relevant results were presented, of which it must be stated not all were entirely relevant. The latter search and more directly concerned to power systems asset management resulted in an even lower yield of just twelve results. A third search term that yielded zero results which was "Holistic Power Systems Asset Management", for brevity this was omitted from the graph below (Figure 1).

The low yield of papers and relevant academic platform to utilise or reference highlights in part a requirement for further investigation, especially in light of such a heavy scholarly reliance on direct activities in managing power systems assets such as maintenance programs/ schedules or maintenance based optimisation [6] and although valid in part such maintenance prominent techniques only represent a

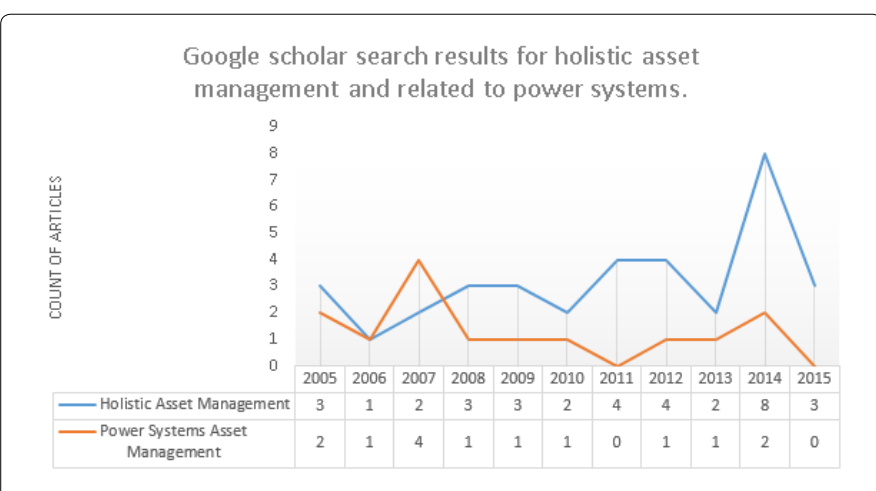

Figure 1: Google scholar search for holistic asset management of power systems articles.

*Corresponding author: James Bruiners, Robert Gordon University, London, London UK, Tel: 01224262000; E-mail: jabruiners@outlook.com

Received May 10, 2016; Accepted May 24, 2017; Published May 29, 2017

Citation: Bruiners J (2017) The Need for a Whole Life Framework in Electrical Power System Asset Management and the Problems with Individual Silo like Asset Management System Contributions. J Electr Electron Syst 6: 225. doi: 10.4172/2332-0796.1000225

Copyright: (c) 2017 Bruiners J. This is an open-access article distributed under the terms of the Creative Commons Attribution License, which permits unrestricted use, distribution, and reproduction in any medium, provided the original author and source are credited. 
single minded view on how to best manage assets through singular engineering disciplines.

Given that the aims and objectives of this research is to provide much needed guidance and method of assisting a power companies optimised approaches towards asset management it is important to build credible, reliable and relevant body of knowledge across all disciplines that apply to the management of power systems assets across the whole life cycle of the assets.

By reviewing the current state of the art in conjunction with the proposed over-developed prominence in singular asset management engineering disciplines enables the gaps in current thinking to be better established. Evaluating these existing gaps in holistically managing power system assets across the lifecycle will be better suited to evaluate the need for creating such holistic management governance through a synthesised framework. Since literature has not dealt with research design in [Asset Management] it would be beneficial to review the literature on research methodology and provide some guidelines [7]. Therefore when approaching this topic of research method relevance it is important to examine a wide platform of necessary facets (research design, literature review, industry and complexities etc.) all embedded in this literature review. This will ensure that the Asset Management as a total approach to managing physical 'things' for the power company can be better established.

By taking a broader approach the research can better establish a solid basis and fundamental framework/approach that intern can be founded both in academia and applied capability (Figure 2).

Although Figure 2 offers the guiding principle and subsequently the most mature approach it isn't sufficient enough for whole life cycle power systems management. This is important as applied to power systems given the long operating time frames for certain assets, such as Power Transformers, Cables, Towers, Control Systems etc., some of the major difference in this case pivots on the application and interpolation of three other major areas:

- Whole-life-cycle considerations for assets, not only in capitally intensive environments.

- Application to electrical power systems assets.

- The complex adaptive system properties that enable a more socio-technical and socio-economic capability.
These additions and changes are represented by the research schematic workflow below and as applied for a suitable approach in researching asset management for power companies across asset whole life cycles. Although the process of research will lend similarly to the framework, it still requires entirely different, more applied and include elements of complex adaptive systems (when desribing low load or distrubuted generation etc.) to the power systems engineering and mangemetn fratenerties, this be more robugstly explored throughout this paper (Figure 3) [7].

\section{Asset Management: General}

An overwhelming focus and attention of the management of physical Assets pivots on and around maintenance centred management [6]. A vast number of papers and research publications in the areas of Asset Management often highlights specific and individual areas such as Maintenance and Risk [7], Procurement [8], Deterioration Mechanics and Sciences surrounding diagnosis [9]. In particular publications point more heavily towards singular fields of engineering disciplines and quite often based on maintenance strategies and implementations of maintenance based asset integrity management [10].

Other asset focused elements such as planning [11]; asset condition and life assessment [12]; renewal/replacement [13]; outsourcing maintenance or contracts [14]; predictive plant maintenance [15]; performance strategy and performance management and measurements; information management amongst others. In large these asset management contributions are mostly conducted in specific asset related activities rather than a wider more enterprise and entire life-cycle systems approach [14-16].

The complex nature of infrastructure and power companies can be likened to that of complex adaptive systems [5], although major acknowledgements in the area of complex adaptive systems in infrastructure are predominately concerned with supply chain Brown et al. [11], and lacking the capability to influence in a system wide focus, especially in regards to whole-life-cycle and holistic asset management. These singular vein approaches of dealing with asset management could be therefore considered a complex problem such as indicated by McArthur et al. [17], examples include interlinked mechanical failures, human judgment, engineering design etc.

As the management of systems through systems design is generally

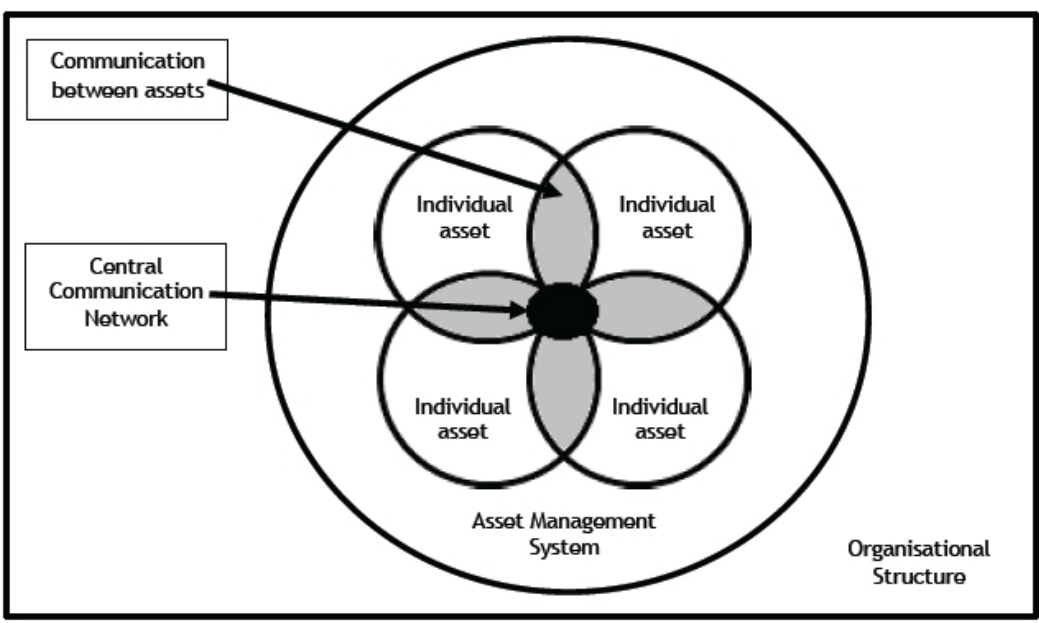

Figure 2: Research workflow for Capital Intensive asset management organisations [5] 


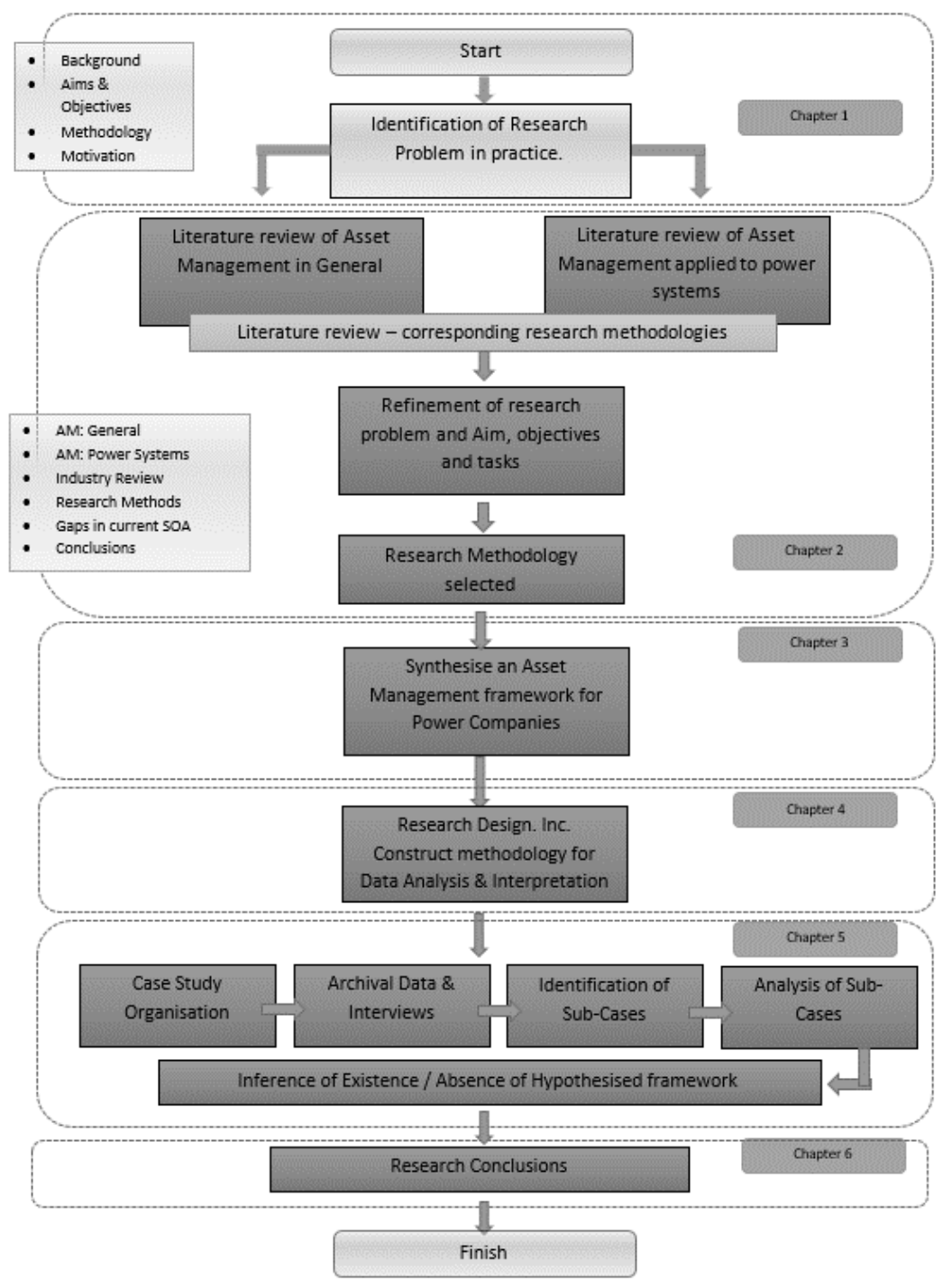

Figure 3: Proposed adaption of report [32] work flow suitable for holistic power systems asset management.

lacking in broadness and definition, likely born out of the seed of a lack of scholarly depth and the complexities [16,18-21] enhances the reason for the needed synthesis of a framework to deal with asset management in more holistic manners.

The Asset Management Council states that asset management is "The life cycle management of physical assets to achieve the stated outputs of the enterprise." Asset Management is "The system that plans and control the Asset-related activities" again upholding the concept that power system asset management represents a more complex system, given this argument it appears that asset management is to be considered a collection of interdependent and connected activities, not just singular activities concatenated [7]. Both go further than most to describe in capital intensive organisations the requirements for additional definition of what asset management in a more holistic lifecycle capacity truly means, but concedes the fact that asset management lacks understanding [7] as there is no widely held understanding of its role in organisational strategy, competitiveness and therefore success. The lack of definition of holistic asset management has led in part to various organisations and groups such as the Institute of Asset Management to form frameworks and incorporate more multidisciplinary sets of interpretations, in essence trying to holistically approach this already broad and undefined term known as Asset Management, Mehairjan et al. [7] as problematic in that asset management is "increasingly a focus of attention in various industries to address interrelationships between the lifecycle of asset and the risks associated with the performance of asset related activities." However, the study falls short as it then proceeds to narrow the scope to only that of which greatly influences strategic elements of capital intensive organisations [22-27].

Asset Management has been viewed historically in a technical activity driven often by engineering functions that represented reliability centred maintenance. Literature appears not broad enough in focus, therefore highlighting a lack of Asset Management in whole life cycle approaches. The maintenance has an important stake hold in Asset Management but is only one part of a much larger 'variable' in effective management of assets across the asset whole life [19].

The holistic requirement and need for an approach in strategically measuring and applying effective asset management across the entire 
of lifecycle of an electrical asset is partially defined as above, yet still not fully developed; Developed meaning the fully integrated and enterprise wide management capability that enables all elements of the company to work together in a well-coordinated and optimised asset management manner.

The term 'holistic' is also an important one, industry specifications such as PAS 55:2008 defines the total life cycle of assets, "The time interval that commences with the identification of the need for an asset and terminates with the decommissioning of the asset or any liabilities there after". Brown et al. [11] demonstrate a key consideration towards holistic asset management, however, as above narrowly focus the efforts towards maintenance, only an element of the asset underlining lifecycle. This is confirmed through the works of Tse et al. [28] stating that "Asset Management is a holistic and interdisciplinary approach that covers the context of engineering asset the whole life cycle of the asset, from the acquisition to the disposal of the asset." Therefore any future research related to the holistic understanding of asset management must fully deal with the entire asset life cycle to be considered holistic.

\section{Asset Management: Power Systems}

The corresponding research that can be applied to holistic asset management and furthermore specifically in the case of power systems is somewhat opaque and weak from an academic viewpoint. This is likely due to the nature of holistic asset management only being discussed in scholarly works in the past decade as and as explained earlier.

The report in ref. [18] goes much further to create a compendium of works and practise that can assist in engineering fraternities, contributing to better understanding of individual realms as related to asset management but offers again no holistic framework or presence for power assets to be holistically represented in sufficient detail.

Again the overwhelming focus leans to a number of individually targeted and often engineering/technical related papers to power systems asset management. Trend analyser's Bonifay this prominence in technical direction [18]. Like in general asset management terms this engineering or technical focus plagues power asset management with the same inability to work holistically across the entire life cycle of the electrical systems assets. Multiple works can be cited in silo type engineering or maintenance/condition monitoring [4], wind power reliability engineering [21], Health Optimisation Modelling [22] and even though they attempt to add value to singular issues within power systems they do not approach the problem in light of a truly holistic capability, nor do they reference higher level reference architectures of which could be derived from and in as much seriously undermining the ability to provide aligned or synchronised asset management capabilities.

This once again adds to the complexity and difficulty as not addressing that asset management is not a single isolated existing entity within an organisation [7]. Furthermore in the power engineering landscape this appears to be an even more underdeveloped. Research topics based majorly on condition monitoring techniques such as Partial discharge [12] or leakage current monitoring. Again only tackling an engineering variable in and amongst the total holistic picture of asset management for power system assets. Reports in ref. [14,17] start to expand on the need for better planning of power systems in light of greater asset management implications through their approach that "Asset management is the art of balancing cost, performance, and risk." However their study dropped back into the engineering lines of reliability centred approaches, likewise inhibiting the ability to develop applied holistic asset management to power systems.

Considering the technical prominence on maintaining assets in light of both general asset management and as related to power systems raises additional gaps, decision making processes "should be incorporated into an overall asset management concept such as described in PAS 55 or ISO 55000" yet offers no relevant framework applicable to power systems life cycle management $[21,22]$. The lack of both academic and applied works to achieve these goals (goals, meaning the overall asset management framework for power companies) underlines the troubles in power company's abilities to effectively apply whole life cycle asset management for its power system assets.

It can also be seen that the emerging research around power systems in light of the term 'Asset Management' lends towards power transformer assets in isolation, reports such as refs. [3,23], in these cases an advancement in engineering technological approaches both fall short of finding the relevant business approaches to supporting the holistic life cycle of the portfolio of assets.

Although, Mehairjan et al. [7] goes some way to initiate the conversation of Asset Management holistically the study falls grossly short in the ability to apply models out of strategic and or capital investment realms, furthermore the study applies it solely to capital intensive organisations and limited at large to strategic only capacities. For example he invites the reader to accept challenges in the life cycle of asset management ownership but reduces the scope by only dealing with capitally intensive situations; this does not apply well when considering power system assets as explained by this work earlier, inevitably leaving a significant gap in knowledge.

Furthermore these difficulties in finding the most fitting adaptation of asset management compound the problem. This especially when considering power engineering as an activity under a broader management, strategic framework or network of interconnected activities to build up best asset management practices. However this fits with the prognosis set forth earlier especially when considering that the topic of holistic asset management has only been developed in literature over the past twelve to thirteen years. Prior research and detailed reports rely heavily on specific related activities, following the relevant and logical adaptations of operations management, engineering and or system engineering.

However, as quantitative and positivist methodologies previous methods maybe there is little in the way of affirming the total complexity of asset management from 'Concept to Disposal' for the power industry. A few recognise the role of qualitative approaches in developing solid research, this needs to be considered when approaching the applicability of research topic in light of the state of the art in regards to asset management as a system and as asset management related to power companies [8].

Two prominent facets apply when approaching the theory of Asset Management which can be considered the discrete contributing activities and the interrelated and correlated system activities that constitutes Asset Management [5]. Before this paper goes someway to prescribing an optimised pathway for these interconnected activities it is important to also highlight that a combination of optimised strategies' must be deployed, therefore any research concerned with bridging this gap must go some way to understand, in the fullest, major and discrete business perspectives in doing so. 


\section{Notable Considerations}

In this section the Asset Management research considerations will be exposed in greater detail, this is especially important when reviewing the general lack of clarity in research towards holistic asset management. This chapter will build on the previous sections in evaluating the nature of asset management, the resulting research and the approaches in Asset Management when considering guiding approaches. Detailing throughout principles that will govern research design in such criteria for example as quantitative and qualitative approaches. Furthermore this chapter will deal with the rationalisation behind case study research as an appropriate research method towards building a stronger body of knowledge through a more refined and better contribution of research [7].

\section{What is Industry Saying About Asset Management}

At times key motivators in developing a research topic are geared toward applying the findings in real life situations [9], often this is in light of the ability to increase decision making capabilities. This effect stipulates that all management research should be applied in essence [26]. Thus the ability to make better decisions in asset management capabilities such as planning, analysis, contracts and asset creation etc. Difficulties in applying academic works with its applied industrial counterpart by trying to close the gap between these two fields [27]. As report [25] acknowledges that, "Applied research is by nature much more problem oriented and could potentially alleviate the problem to value the applicability of envisioned research output". This gap between the research topics as highlighted in previous sections and as related to singular silos of asset management activities has widely led to the creation of arbitrary consultative frameworks as prescribed by the likes of the Institute of Asset Management, the Asset Management Council and the Asset Institute. The lack of holistic asset management frameworks in scholarly terms represents a truly challenging situation for the industries that could be suited to implementing such frameworks. ISO 55000 and PAS 55:2008 represent such standards or frameworks to assist, but themselves are not strongly implemented guidelines. Although these frameworks go some way to assist companies in better managing the holistic picture they fall short of providing the necessary guidance or rigorous testing of a dedicated research thesis.

\section{Research Methods}

This section will review the effectiveness of case study research in light of previous works and make critical analysis towards how to best approach the proposed value as in light of this thesis. Due to the lack of maturity in the research of holistically applied asset management or indeed as applied to power systems creates a requirement to evaluate the mixtures of research methodologies. However, it is clear that the reports in refs. $[7,27,28]$ do employ case study with hypothesised model.

Fortunately there is a wealth of new and historic material, research and information regarding principles of case study research methodologies as applied to engineering, power and related business systems. The importance of stipulating that none of the methods evaluated are thought to build a singular body of knowledge, considering the infancy in scholarly remit, the 'blended approach' to research methods will deliberately expand the capability to look further in building the most effective case study research possible for the hypothesis [19,29]. This will manifest itself as an applied mixture of the best suited research methods in essence to facilitate an effective, broader ability to utilise case study research. As ref. [5] prescribes a retroductive strategy with case study method to yield an appropriate manner in which to approach the research method. As the prior scholarly evidence demonstrates initial gaps in research, both as applied to asset management and asset management as applied to power systems assets. This is especially prevalent when considering the need to utilise, at times best practices and or established techniques from other research as part of any holistic asset management framework [28-30]. When considering the concept of retroduction in this manner it becomes apparently clear in light of the argument that "the dualism between pure inductive and deductive research processes can be overcome by introducing retroduction [30-32]. Retroduction makes this research possible by the process that characterized the linking of evidence (induction) and social theory (deduction) in a continually evolving, dynamic process." Thus report in ref. [28] approach is supported by the fact that Power Companies comprise of socio-technical diversity highlights and representative of complex adaptive systems (Figure 4) [11].

However as reported in ref. [29] this does not go far enough in holistically explaining the framework that builds up effective asset management and all the phenomenon, especially not nearly enough to apply to power companies. Given the explanation offered up by Smith and Stirling [33] that a case study represents an empirical inquiry that investigates a contemporary phenomenon in depth and within its reallife context, especially when the boundaries between phenomenon and context are not clearly evident, would therefore serve an appropriate research method for asset management. Taking a hypothesised model

\section{The research process}

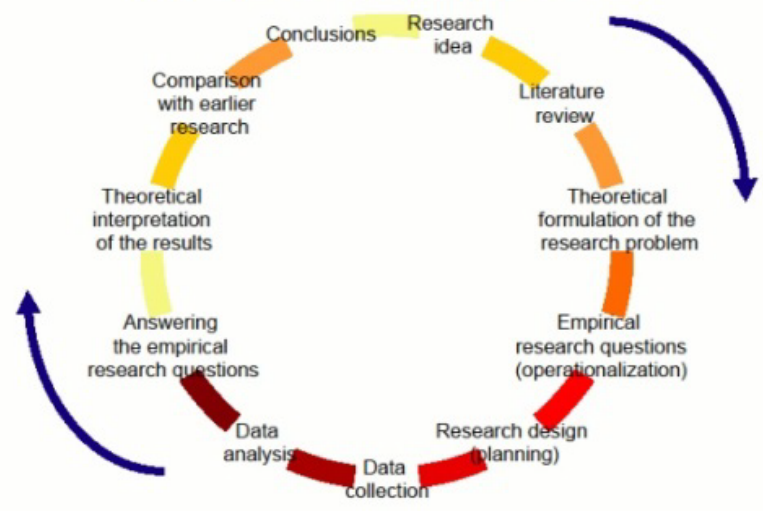

Figure 4: Report [25] research process method. 
Citation: Bruiners J (2017) The Need for a Whole Life Framework in Electrical Power System Asset Management and the Problems with Individual Silo like Asset Management System Contributions. J Electr Electron Syst 6: 225. doi: 10.4172/2332-0796.1000225

Page 6 of 8

and merging with case study approach accordingly to Smith and Stirling [33] empowers the research in

- Coping with the technically distinctive situation in which there will be many more variables of interested than data points, and as one result.

- Relies on multiple sources of evidence, with data needing to converge in a triangulating fashion, and as another result.

- Benefits from the prior development of theoretical propositions to guide data collection and analysis.

An approach grafted from hypothesised model and tested through case study method works well $[14,31]$. That is that the combination of hypothesised model, as expressed as a holistic framework created by the author and tested through a case study offers a well attuned mechanism to research the holistic asset management picture in light of the real world context [33-36]. Although the research method shown above is very much applicable for the purpose of power companies operating in capital investment only activities, it is not inclusive enough to ensure whole-life-cycle optimisation of power systems, assets and or power companies throughout the entire life cycle. Entire life cycle in this case as specified by the Figure 5 and as can be schematically seen in the diagram.

Therefore the studies breadth and specificity towards power assets must therefore be extended to sufficiently align with the aim and objectives of this thesis. Figure 4 shows a method on researching the role of asset management for capital Intensive organisations highlights the limited scope of asset management and organisational strategy. Therefore although the method is useful and applicable the application must be suited to include those companies operating, owning or engaging in works directly related to power systems assets in greater detail. Hence the retrofit approach towards reviewing both Asset
Management in general academic application and as applied to power systems companies.

\section{Gaps in the Current State of the Art}

Given the clear indications and initial evidence for lack of knowledge regarding holistic asset management highlights a dual natured challenge, one being asset management as a holistic capability for companies and secondarily as applied directly to power companies. This literature review and research analysis highlights multiple gaps in both the asset management in general and as applied in the power systems fraternities of which can be summarised into two major elements.

Firstly as highlighted by the relative lack of holistic capabilities also secondarily compounded by an inability to apply credible holistic asset management across the asset lifecycle to power systems assets $[37,38]$. These gaps are to be expected given the relative lack of research conducted over the past decade and given such predominate previous research leaning towards engineering disciplines [26].

In addition and when considering the application of power systems asset management clearly identifies part of the problem when approaching power systems holistic asset management [34]. That is the lack of a corresponding holistic framework to utilise or apply. Some have attempted to morph a specific industrial concept to loosely fit elements of the power industry as demonstrated in report [35] yet again nothing specifically applied for power system assets.

In part this could be due to the complexity that surrounds decision making processes when concerning power system assets and as in the real world system wide setting. Given for example that power assets can represent multi-faceted business/government requirements and act as a provision of power to provide commerce and as a national/ international infrastructure asset. As report in ref. [3] identifies this

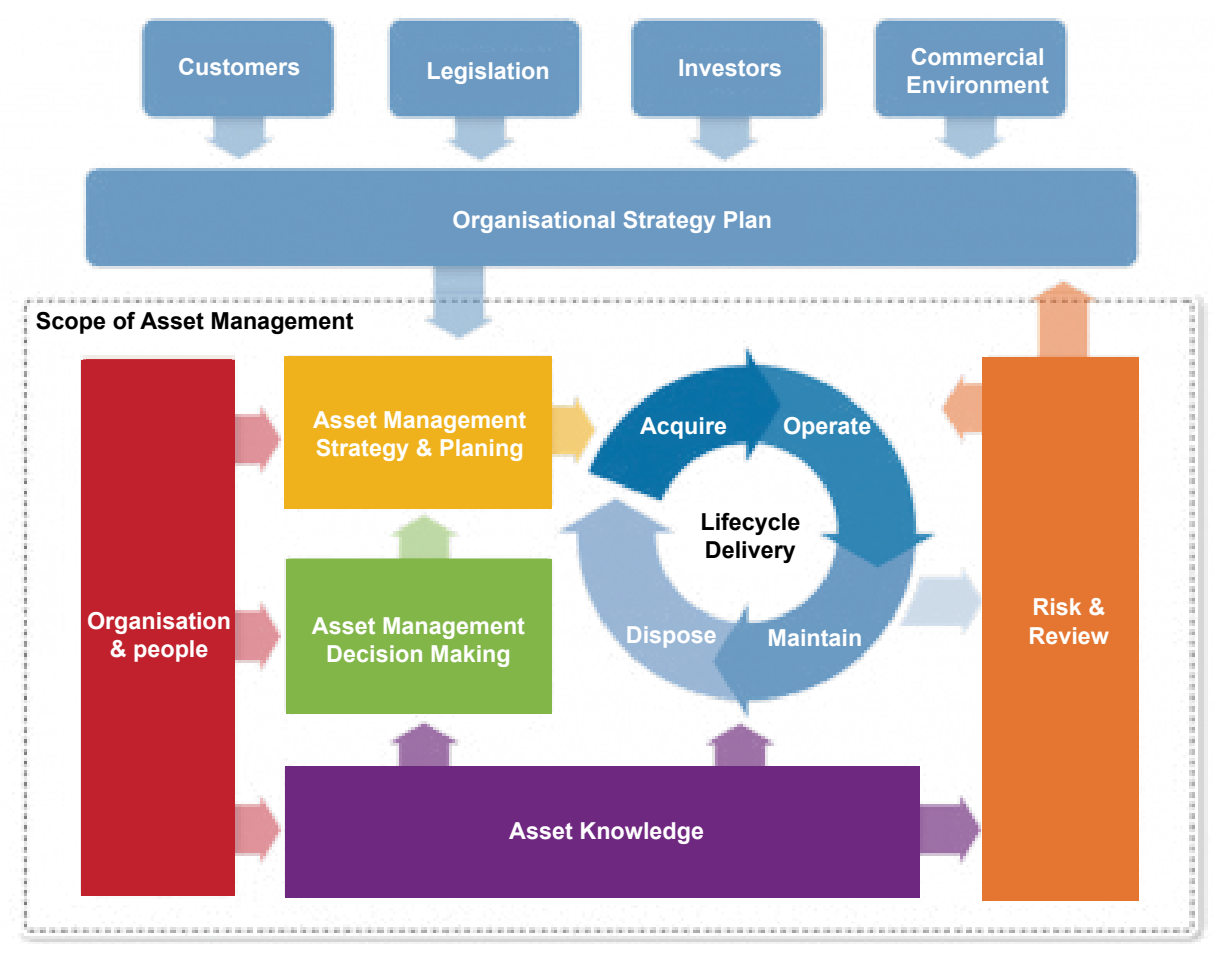

Figure 5: The Institute of Asset Management conceptual model. 
challenge by calling out the complexity, "infrastructure management decision making is inherently an integrated process that requires the assimilation of a multitude of data, processes, and software systems." In consideration it can be said due to the applied nature of asset management of power system assets any suitable framework must inherit from an overarching capability that is holistically asset management driven.

Therefore the contribution of this research will be to fill two major challenges facing power systems assets across the lifecycle, that is:

- To ensure that a holistic full life-cycle asset management framework is developed and rigorously tested that,

- Applies to power companies.

\section{Conclusion}

The gaps in literature related to holistic asset management must take a complex system approach in prescribing a framework that reaches across the life cycle of power assets. That is the literature reviewed clearly identifies how in engineering terms individual areas of asset management can be approached and the manners in which these individual like contributions are focused in 'silo' like approaches. However, without the relevant overarching systems framework dealing with the combined approach to holistic asset management the optimisation of assets across the entire power asset portfolio cannot be fully realised.

In summary of the above paragraphs it is considered that effective Asset Management and the necessary controls are not represented solely by singular or independent activities, departments and or processes within an organisation. As highlighted in previous research these technical elements of asset management fall short on multiple fronts as the wider complex adaptive system natures are not taking widely into consideration as governance. Given the complex nature of the system concerned a complex socio-technical approach is the preferred approach in securing a more holistic framework, in achieving this end it has been identified that a retroductive case study and synthesised framework as the most fitting approach to ensure an integrated framework that included business and engineering elements to reach the aim. The synthesis and design of processing networks is a complex and multidisciplinary problem, which involves many strategic and tactical decisions at business (considering financial criteria, market competition, supply chain network, etc.) and engineering levels (considering synthesis, design and optimization of production technology, $R \& D$, etc.), all of which have a deep impact on the profitability [30]. It is the conclusion of this literature review that a clear and evident gap exists in the capabilities of power companies to manage assets in a truly whole-life-cycle manner and although it is true to say that Physical Assets are the centre piece of management in this thesis ignoring the social or human presence geared in business environments is an underlining problem when creating a holistic framework for whole-life-cycle for power assets in the current state of the art. Especially when considering the nature of the human interaction with these physical assets throughout the life-cycle.

Given the extensive individual electrical and industrial engineering contributions have resulted in predominately linear improvements in the corresponding disciplines and in light of many a decade of 'industrial age like engineering' research concludes that science has yet to build a capacity of power system organisations to face the challenges of the present and future with sufficient capability, furthermore highlighting the requirement of a new research project.
Therefore the major gaps as seen by this review in scholarly terms clearly identify two major areas of which to increase in asset management capability, knowledge and research. That is in constructing a relevant asset management framework consisting largely of two major elements:

- Construct a holistic framework according to general terms applied in Asset Management whilst ensuring,

- Appropriateness of the framework to optimise asset management across power systems assets specifically.

The ability to do this constitutes a wide multi-disciplinary, multifaceted, inter-connected complex system and to include understanding of research and effects across the model proposed during research, this is due to the expansive nature of Asset Management in general when creating a holistic framework. Often asset life cycle is separated into what might be considered manageable technical segments such as Maintenance or Finance, outlined above in the problem statements. Definitions from various commercial sector bodies highlight such elements as design, procurement, build and disposal as independent activities that make up a larger framework. The effective management of these cycles constitutes the broader pathway to effective strategic asset management [24].

It is true that organisations concerned with Asset Management require a decisive capability in approaching decisions, strategies, projects, organisation, information technological implementations, replacements, or end of life capabilities if optimised asset management in such settings is to be realised [17]. In this approach it is clear that asset management as applied in a system wide context is highly complicated and further represents cross collaboration of system wide expressions and interactions.

When considering how organisations may approach these asset management facets we need to expand on the 'how' or 'ways' of approaching such enhancements. For example on the approach to upgrading, expanding on supportive processes, business and or organisational capacity in ways to help the delivery of enhanced underlying asset management systems, naturally these decisions will have consequences on other areas of the system. Another example could be, such as outsourcing maintenance of Utility work to third parties will have a myriad of effects on other areas of the power company. Or perhaps when implementing a computerised maintenance management system or other asset related information systems to compliment the drive towards ISO 55000 information management compliance. Again these system contributions have multiple touch points and influence in the overall optimisation of any whole life cycle asset management system. More importantly though is to correlate the enhancement in light of both of the above as opposed to 'silo' and independently approached technical elements of maintaining assets only.

This research will aid in exposing the criticality of taking the broad approach in from the total view of disciplines and applications of asset management decision enhancement as a complex adaptive system, however, returning and applying throughout to the management of power assets. Subsequently, drawing on the experiences and insights from such disciplines as engineering, risk management, finance, and business development [36].

An applied research pattern is required to help secure the widest possible understanding of influence when considering holistic Asset Management, especially since many of the challenges appear contextual and to be seen in light of their activity, or field of activities is required in understanding the total combined picture - a case where the total is 
Citation: Bruiners J (2017) The Need for a Whole Life Framework in Electrical Power System Asset Management and the Problems with Individual Silo like Asset Management System Contributions. J Electr Electron Syst 6: 225. doi: 10.4172/2332-0796.1000225

Page 8 of 8

worth more than the sum of the parts and suggests a strong comparison to the likes of complex adaptive systems.

Therefore this requires that both researcher and the party responsible in the identification of the problem must be placed in the market itself, in real terms meaning a company that works with power systems in critical remits or as part of its core requirement to function. Both to fully rationalise the potential benefits and rewards from such a holistic framework.

This literature review concludes that substantial academic and industry value will be generated from applying a synthesised framework to assist the system of asset management, whilst helping rationalise assets and the management of assets throughout, supporting in essence the evolution towards optimised asset management for power companies. This approach will also inevitably educate-on-route rather than just collect, analyse and cast aspersions of theoretical nature solely. In taking this approach a truly representative model will absorb the complexity required whilst ensure the increases in and enhancements through the organisational management of the entire asset management system by a system and by a new synthesised model [32]

\section{References}

1. Kirova V, Kirby N, Kothari D, Childress G (2008) Effective requirements traceability: Models, tools, and practices. Bell Labs Technical Journal 12: 143-157.

2. Mazak A, Kargl H (2012) Cognitive Engineering meets Requirements Engineering, Bridging the Traceability Gap. ICSEA 2012, The Seventh International Conference on Software Engineering Advances.

3. Shahidehpour M, Ferrero R (2005) Time management for assets: chronological strategies for power system asset management. Power and Energy Magazine 3: $32-38$

4. Jahromi A, Piercy R, Cress S, Service J, Fan W (2009) An approach to powe transformer asset management using health index. Electrical Insulation Magazine 25: 20-34.

5. Amin SM, Wollenberg BF (2005) Toward a smart grid: power delivery for the 21st century. Power and Energy Magazine, IEEE 3: 34-41.

6. Brown T, Beyeler W, Barton D (2004) Assessing infrastructure interdependencies: the challenge of risk analysis for complex adaptive systems. International Journal of Critical Infrastructures 1: 108-117.

7. Mehairjan RPY, Smit JJ, Djairam D (2014) Trends in Risk-Based Substation Asset Management \& Lifetime Monitoring. International workshop on power transformers.

8. Calder BJ, Phillips LW, Tybout AM (1981) Designing research for application. Journal of consumer research, pp: 197-207.

9. Goel L, Aparna VP, Wang P (2007) A framework to implement supply and demand side contingency management in reliability assessment of restructured power systems. Power Systems, IEEE Transactions 22: 205-212.

10. Hastings NAJ (2009) Physical asset management. Springer Science \& Business Media

11. Brown R, Spare J (2004) Asset management, risk, and distribution system planning. Power Systems Conference and Exposition.

12. Halfawy MR (2008) Integration of municipal infrastructure asset management processes: challenges and solutions. Journal of Computing in Civil Engineering 22: $216-229$

13. Sather B (1999) Retroduction: an alternative research strategy? Business Strategy and the Environment 7: 245-249.

14. Campbell JD, Jardine AKS, McGlynn J (2011) Asset management excellence: optimizing equipment life-cycle decisions. CRC Press, Boca Raton, Florida, United States.

15. Schuman CA, Brent AC (2005) Asset life cycle management: towards improving physical asset performance in the process industry. International Journal of Operations \& Production Management 25: 566-579.
16. Baker MJ (2000) Selecting a research methodology. The marketing review 1 373-397.

17. McArthur SDJ, Davidson EM, Catterson VM, Dimeas AL, Hatziargyriou ND et al. (2007) Multi-agent systems for power engineering applications- Part II: technologies, standards, and tools for building multi-agent systems. Power Systems, IEEE Transactions 22: 1753-1759

18. Pagani GA, Aiello M (2013) The power grid as a complex network: a survey. In: Physica A: Statistical Mechanics and its Applications. Elsevier, pp: 2688-2700.

19. Blanchard BS (2009) Maintenance and support: a critical element in the system life cycle." Systems Engineering and management for Sustainable Development-Volume 2.

20. Madu CN (2000) Competing through maintenance strategies. Internationa Journal of Quality \& Reliability Management 17: 937-949.

21. Puletti F, Olivieri M, Cavallini A, Montanari GC (2006) Risk management of HV polymeric cables based on partial discharge assessment. In: Proc. IEEE PES Transmission Distribution Conference, pp: 626-633.

22. Vladimir Frolov, David Mengel, Wasana Bandara, Yong Sun, Lin Ma (2010) Building an ontology and process architecture for engineering asse management. Engineering Asset Lifecycle Management. Springer London, pp: 86-97.

23. Choubey SK (2011) System and method to calculate procurement of assets US Patent No 8032401.

24. Cigre (2014) Contracts for Outsourcing Utility Maintenance Work.

25. Abu-Elanien AEB, Salama MMA (2010) Asset management techniques for transformers. Electric power systems research 80: 456-464.

26. Runeson P, Höst M, Sjoberg D (2009) Guidelines for conducting and reporting case study research in software engineering. Empirical software engineering 14: 131-164.

27. Dooley KJ (1997) A complex adaptive systems model of organization change Nonlinear Dynamics, Psychology, and Life Sciences 1: 69-97.

28. Tse PWT, Mathew J, Wong K, Lam R, Ko CN (2013) Engineering Asse Managment - Systems, Professional Practices and Certification. Springer.

29. Baughman ML, Siddiqi SN (1991) Real-time pricing of reactive power: theory and case study results. Power Systems, IEEE Transactions 6: 23-29.

30. Quaglia A, Sarup B, Sin G, Gani R (2012) Integrated business and engineering framework for synthesis and design of enterprise-wide processing networks. Computers \& Chemical Engineering 38: 213-223.

31. Skinne M, Kirwan A, William J (2011) Challenges of developing whole life cycle cost models for Network Rail's top 30 assets. IET and IAM Asset Management Conference.

32. Starkey K, Paula M (2001) Bridging the relevance gap: Aligning stakeholders in the future of management research. British Journal of management 12: S3-S26.

33. Smith A, Stirling A (2008) Social-ecological resilience and sociotechnical critical issues for sustainability governance. STEPS Centre.

34. El-Akruti KO (2012) The Strategic role of engineering asset management in capital intensive organisations. University of Wollongong, Northfields Ave, Wollongong, Australia.

35. Faiz RB, Edirisinghe EA (2009) Decision making for predictive maintenance in asset information management. Interdisciplinary Journal of Information, Knowledge, and Management, pp: 23-26.

36. Schneider J, Gaul A, Neumann C, Hogräfer J, Wellßow W (2006) Asse management techniques. International Journal of Electrical Power \& Energy Systems 28: 643-654.

37. Hooper R, Armitage R, Gallagher A, Osorio T (2009) Whole-life infrastructure asset management: good practice guide for civil infrastructure. CIRIA

38. El-Akruti Khaled O, Dwight R (2010) Research methodologies for engineering asset management. ACSPRI Social Science Methodology Conference. 